\title{
Dynamic Micelles of Mannoside Glycolipids are more Efficient than Polymers for Inhibiting HIV-1 trans-Infection
}

\author{
Evelyne Schaeffer, ${ }^{*}{ }^{\dagger}$ Laure Dehuyser, ${ }^{\ddagger}$ David Sigwalt, ${ }^{\ddagger}$ Vincent Flacher, ${ }^{\dagger}$ Serena Bernacchi, ${ }^{\S}$ \\ Olivier Chaloin, ${ }^{\dagger}$ Jean-Serge Remy, ${ }^{\ddagger}$ Christopher G. Mueller, ${ }^{\dagger}$ Rachid Baati, ${ }^{\ddagger}$ and Alain Wagner ${ }^{\ddagger}$ \\ ${ }^{\dagger}$ Laboratory of Immunopathology and Therapeutic Chemistry, CNRS UPR 3572/Laboratory of Excellence MEDALIS, Institut de \\ Biologie Moléculaire et Cellulaire, 15 rue René Descartes, 67000 Strasbourg, France \\ ${ }^{\ddagger}$ Laboratory of Functional Chemo Systems and Laboratory Vectors: Synthesis and Therapeutic Applications, CNRS-University of \\ Strasbourg, UMR 7199/Laboratory of Excellence MEDALIS, Faculté de Pharmacie, Université de Strasbourg, 74 route du Rhin, \\ 67400 Illkirch, France
}

${ }^{\S}$ Architecture et Réactivité de l'ARN, CNRS UPR 9002, Institut de Biologie Moléculaire et Cellulaire, Strasbourg, France

\section{Supporting Information}

\begin{abstract}
Mannoside glycolipid conjugates are able to inhibit human immunodeficiency virus type 1 (HIV-1) trans-infection mediated by human dendritic cells (DCs). The conjugates are formed by three building blocks: a linear or branched mannose head, a hydrophilic linker, and a 24-carbon lipid chain. We have shown that, even as single molecules, these compounds efficiently target mannose-binding lectins, such as DC-specific ICAM-3-grabbing nonintegrin (DC-SIGN) important for HIV-1 transmission. With the goal to optimize their inhibitory activity by supramolecular structure formation, we have compared saturated and unsaturated conjugates, as single molecules, self-assemblies of dynamic micelles, and photopolymerized cross-linked polymers. Surface plasmon resonance showed that, unexpectedly, polymers of trivalent

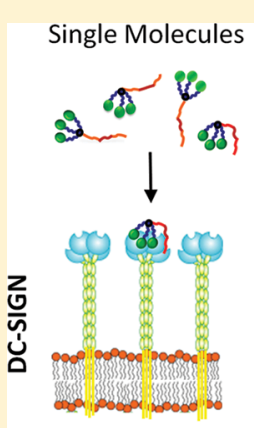

Low
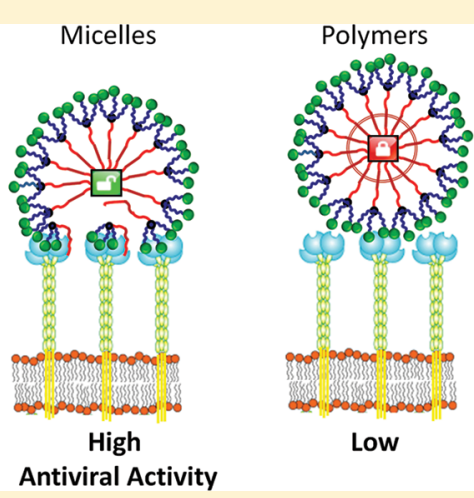

Antiviral Activity conjugates did not display a higher binding affinity for DC-SIGN than single molecules. Interactions on a chip or in solution were independent of calcium; however, binding to DCs was inhibited by a calcium chelator. Moreover, HIV-1 trans-infection was mostly inhibited by dynamic micelles and not by rigid polymers. The inhibition data revealed a clear correlation between the structure and molecular assembly of a conjugate and its biological antiviral activity. We present an interaction model between DC-SIGN and conjugates-either single molecules, micelles, or polymers-that highlights that the most effective interactions by dynamic micelles involve both mannose heads and lipid chains. Our data reveal that trivalent glycolipid conjugates display the highest microbicide potential for HIV prophylaxis, as dynamic micelles conjugates and not as rigid polymers.
\end{abstract}

\section{INTRODUCTION}

Research in the area of nanopharmaceuticals has witnessed an expansive growth. The elaboration of complex molecular assemblies of size scales between 1 and $100 \mathrm{~nm}$ promises new advances for therapy and prophylaxis of microbial infections. For instance, various gold, silver, dendrimer, and fullerene-based nanotechnologies are being developed as nanomicrobicides against human immunodeficiency virus type-1 (HIV-1) infections. ${ }^{1}$ These studies respond to the urgent need to develop safe and effective mucosal microbicides, to either inactivate the virus or block its attachment, cell entry, replication, and transmission., ${ }^{2,3}$ During the early phase of sexual transmission, dendritic cells (DCs) play an essential role. They are among the first cells to be infected ${ }^{4-7}$ and contribute to viral dissemination by their ability to capture and transport virions into lymph nodes, eventually mediating infection of new target cells. $^{8-10}$ This so-called trans-infection can occur by distinct pathways. The main mechanism implies the DC- specific intercellular adhesion molecule 3 [ICAM-3]-grabbing nonintegrin (DC-SIGN), a C-type lectin highly expressed at the surface of DCs. ${ }^{11-13}$ HIV-1 is captured via DC-SIGN and is then transferred to target $\mathrm{CD}^{+}$cells through cell-cell interactions. $^{10,14}$

The DC-SIGN receptor is a membrane protein with an extracellular C-terminus carbohydrate recognition domain (CRD), a neck region, and a short amino-terminal cytoplasmic tail. The CRD tetramer specifically recognizes glycosylated proteins and ligands bearing mannose and related sugars. It interacts with high-mannose structures of glycoproteins in a calcium-dependent manner and also recognizes fucose-based ligands such as Lewis $\mathrm{X}^{15,16}$ The CRD domain binds envelope glycoproteins expressed on viruses (HIV-1, Ebola, Hepatitis C,

Received: February 12, 2013

Revised: September 23, 2013

Published: October 18, 2013 
and Dengue) and many other pathogens. ${ }^{17,18}$ In the case of HIV-1, the highly glycosylated glycoprotein gp120 exposed on the surface of the virion interacts with the carbohydrate -binding domain of DC-SIGN at the surface of DCs. ${ }^{19-21}$

The design of DC-SIGN antagonists and carbohydrate analogues to target distinct receptors has been the focus of extensive research. ${ }^{22}$ Efforts were first undermined by the intrinsic low affinity (millimolar binding constants) of monovalent carbohydrates. The multivalent effect greatly helped improve binding affinities by orders of magnitude, ${ }^{16}$ so that multivalent carbohydrate-containing molecules could efficiently target DC-SIGN. Mannose polyvalent dendrimers and monodisperse compounds interfere in vitro with the interaction between DC-SIGN and gp120 proteins. $^{23-26}$ Multivalent mannoside polymers inhibit HIV trans-infection mediated by DC-SIGN-expressing cell lines. Gold mannoglyconanoparticles block HIV trans-infection mediated by Raji-DCSIGN cells ${ }^{27}$ and are endocytosed in monocyte-derived immature DCs by DC-SIGN-dependent and -independent pathways. $^{28}$ Mannosyl glycodendritic structures based on dendritic polymers functionalized with mannose also reduce HIV trans-infection mediated by THP-1-DC-SIGN cells. ${ }^{29}$ One of these multimeric glycomimetic DC-SIGN ligands inhibits HIV-1 trans-infection of CD4+ T lymphocytes and prevents HIV-1 infection of human cervical tissues. ${ }^{30}$

We have recently reported the synthesis of mannoside glycolipid conjugates. These compounds exhibit unusual properties based on the cooperation between the mannose head and the lipid chain. Thanks to this original concept, they target DC-SIGN with micromolar affinities and inhibit HIV-1 (R5 and X4 strains) trans-infection as single molecules and as self-assembled micelles, with $\mathrm{IC}_{50} \mathrm{~S}$ in the low micromolar range. $^{25}$

In this report, we aimed at enhancing the antiviral activity of our conjugates, by creating multimers of mannoside glycolipids (micelles and polymers) expected to bind to DC-SIGN with higher affinities. By building on our previous observation ${ }^{25}$ that micelles containing an unsaturated versus a saturated lipid chain had a 10-fold lower critical micelle concentration (CMC), we first synthesized an unsaturated trivalent glycolipid and compared it with its saturated homologue. Second, because we found that photopolymerization of diynes motifs leads to the reticulation of amphiphilic micelles and decreases their CMC about 10-fold without affecting their shape and size, ${ }^{31,32}$ we hypothesized that the inhibitory activity of our compounds could be optimized by a supramolecular structure of crosslinked polymers. We evaluated saturated and unsaturated conjugates, as single molecules, dynamic micelles, and photopolymerized cross-linked polymers, with respect to their affinity for DC-SIGN and their ability to inhibit HIV-1 trans-infection. Our data demonstrate that dynamic micelles display better antiviral abilities than rigid polymers. They highlight a clear correlation between the molecular structure of conjugates and their antiviral activity.

\section{EXPERIMENTAL PROCEDURES}

Compound synthesis and characterization are described in Supporting Information.

Critical Micelle Concentrations (CMC). CMC were determined as described, ${ }^{25}$ using conjugate samples dissolved in water $(1 \mathrm{~mL})$, with concentrations ranging from 1.0 to 0.001 $\mathrm{mg} / \mathrm{mL}$.
Dynamic Light Scattering (DLS). The hydrodynamic diameters of micelles were measured in water by DLS measurements using a Zetasizer Nano ZS system (Malvern Instruments) as described. ${ }^{31}$

Polymerization of Micelles. The unsaturated conjugates were dissolved in water above the micellar concentration (1 $\mathrm{mM})$. Polymerization was performed by irradiation in a UV chamber $(254 \mathrm{~nm}, 48 \mathrm{~W})$ for $10 \mathrm{~h}$. The resulting solutions were of yellow color, due to the formation of polymers containing ene-ynes bonds. This process was reproduced on several batches that always presented the same functional characteristics (DLS, biological activity). Concentrations were calculated as concentrations of monomers before polymerization.

Transmission Electronic Microscopy (TEM). Compounds $(5 \mu \mathrm{L} ; 0.5 \mathrm{mg} / \mathrm{mL})$ were spread on a copper/rhodium grid covered with a carbon film. Micelles were negatively stained with uranyl acetate $(2 \% ; 50 \mu \mathrm{L})$. TEM images were obtained using a Philips CM 120 microscope.

Surface Plasmon Resonance (SPR). SPR experiments were performed using a Biacore 3000. Immobilization of recombinant human DC-SIGN (Lys62-Ala404; R\&D Systems) or recombinant human macrophage mannose receptor $M R$ (Leu19-Lys1383; R\&D Systems) on a CM5 sensor chip (GEHealthcare, Uppsala, Sweden) was performed by injecting 70 $\mu \mathrm{L}$ of DC-SIGN, MR, or BSA $(50 \mu \mathrm{g} / \mathrm{mL}$ in formate buffer, $\mathrm{pH}$ $4.3)$ onto the surface activated with $N$-ethyl- $N^{\prime}$-dimethylaminopropyl carbodiimide (EDC)/N-hydroxysuccinimide (NHS), which gave a signal of approximately $8000 \mathrm{RU}$. This was followed by $20 \mu \mathrm{L}$ of ethanolamine hydrochloride, $\mathrm{pH} 8.5$, to saturate the free activated sites of the matrix. Biosensor assays were performed with HEPES-buffered-saline (10 mM HEPES, $150 \mathrm{mM}$ sodium chloride, $\mathrm{pH}$ 7.4) containing $0.005 \%$ surfactant $\mathrm{P} 20$ and $5 \mathrm{mM} \mathrm{CaCl}$ (or no $\mathrm{CaCl}_{2}$ as indicated) as running buffer. All binding experiments were carried out at $25^{\circ} \mathrm{C}$ with a constant flow rate of $20 \mu \mathrm{L} / \mathrm{min}$. The compounds dissolved in the running buffer $(0.39$ to $50 \mu \mathrm{M})$ were injected for $3 \mathrm{~min}$, followed by a dissociation phase of $3 \mathrm{~min}$. The sensor chip surface was regenerated after each experiment by injecting $10 \mu \mathrm{L}$ of EDTA $0.5 \mathrm{M} \mathrm{pH}$ 8.0. A simple channel activated by EDC/NHS and deactivated with ethanolamine was used as control. The kinetic parameters were calculated using the BIAeval 4.1 software. Analysis was performed using the simple Langmuir binding model with separate $k_{\mathrm{a}} / k_{\mathrm{d}}\left(k_{\mathrm{on}} / k_{\text {off }}\right)$. The specific binding profiles were obtained after subtracting the response signal from the control channel and from blank-buffer injection. The fitting to each model was judged by the $\chi^{2}$ value and randomness of residue distribution compared to the theoretical model (Langmuir binding 1:1).

Steady State Fluorescence Spectroscopy. Fluorescence measurements were recorded in quartz cells at $20 \pm 0.2{ }^{\circ} \mathrm{C}$ on a Fluoromax-4 fluorometer (HORIBA Jobin-Yvon Inc., NJ, USA). The excitation wavelength was set at $295 \mathrm{~nm}$ for selective excitation of tryptophan residues of DC-SIGN. The emission wavelength was scanned from 310 to $450 \mathrm{~nm}$; the integration time was $0.1 \mathrm{~s}$, and the excitation and emission bandwidths were $5 \mathrm{~nm}$. Fluorescence titrations were performed by adding increasing amounts of conjugate $(0.01$ to $10 \mu \mathrm{M})$ to DC-SIGN $(0.1 \mu \mathrm{M}$ final) in PBS supplemented or not with $\mathrm{CaCl}_{2}(5 \mathrm{mM})$, as indicated. Fluorescence intensities were corrected for buffer fluorescence and dilution effect. To determine the binding parameters of the conjugates to DCSIGN, we measured the decrease of the fluorescence intensity, $I$, at a fixed concentration of protein in the presence of 


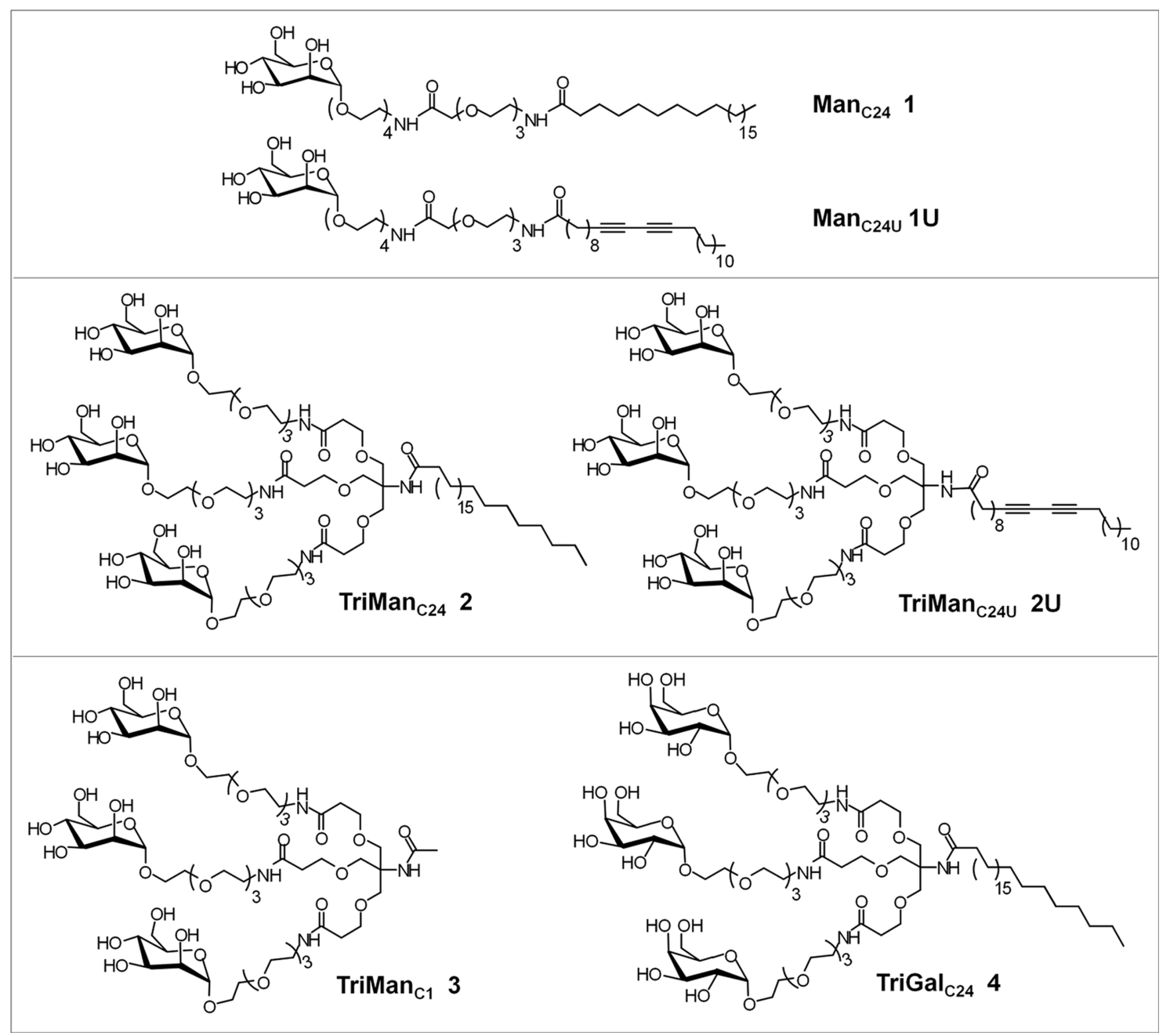

Figure 1. Structure of conjugates.

increasing conjugate concentrations. The fluorescence intensity was then converted into the intrinsic fluorescence quenching $Q_{\text {obs }}: Q_{\text {obs }}=\left(\left(I-I_{0}\right) /\left(I_{0}\right)\right)$, with $I_{0}$ corresponding to the protein fluorescence intensity in the absence of conjugate. Scatchard equation was used to fit the protein/conjugate titration data:

$$
v=\frac{K_{\mathrm{obs}} L}{1+K_{\mathrm{obs}} L}
$$

where $K_{\mathrm{obs}}$ is the observed affinity and $L$ corresponds to the free protein concentration. In order to check for the presence of two classes of binding sites for a conjugate, we plotted the fraction of bound protein versus the unbound protein fraction. When the plot yielded consistently a linear pattern, we estimated the presence of only one binding site.

Cell Culture. MAGI-CCR5 cells are HeLa-CD4-LTR-LacZ cells expressing both CXCR4 and CCR5 coreceptors (received from NIH AIDS Research and Reference Program, from Dr. Julie Overbaugh). ${ }^{33}$ HEK293T cells were used for HIV-1 production. MCF-7 cells were used for viability tests. All cell lines were cultured at $37{ }^{\circ} \mathrm{C}$ and $5 \% \mathrm{CO}_{2}$ in Dulbecco's modified Eagle's medium (DMEM) supplemented with gentamycin and $10 \%(\mathrm{v} / \mathrm{v})$ heat-inactivated fetal bovine serum (FBS).
Human Monocyte-Derived Dendritic Cells (DCs). DCs were generated from elutriated monocytes obtained from the French Blood Bank (Etablissement Français du Sang, Strasbourg, France) as described. ${ }^{25}$

Cellular Binding Assays with Fluorescent Conjugates. A succidinyl ester of Alexa Fluor 633 (AF633; Invitrogen) was coupled with conjugates 2, 2UP, or with mannan (SigmaAldrich) according to the manufacturer's instructions. Briefly, compounds were incubated overnight with AF633 succidinyl ester (0.05 mol equiv) in $\mathrm{H}_{2} \mathrm{O}(200 \mu \mathrm{L})$ with catalytic quantities of DMAP $(10 \% \mathrm{w} / \mathrm{w})$. Coupled conjugates were then purified on PD-10 desalting columns (GE Healthcare) with quantitative yields.

Elutriated monocytes or immature DCs $\left(10^{5}\right.$ cells/well in $100 \mu \mathrm{L}$ of cell culture medium) were seeded in 96-well plates. Compounds 2/AF633 and 2UP/AF633 $(0,5$, or $50 \mu \mathrm{M})$ or Mannan/AF633 $(500 \mu \mathrm{M})$ were added, and the cells were incubated for $1 \mathrm{~h}$ at $4{ }^{\circ} \mathrm{C}$ or at $37{ }^{\circ} \mathrm{C}$, in the presence or absence of EDTA $(50 \mathrm{mM})$. Cells were harvested and the geometric mean fluorescence intensity of live cells was quantified by flow cytometry in the FL-4 channel.

Flow Cytometry Analyses. Experimental data was acquired on a FACScalibur (Becton-Dickinson) and analyzed with CellQuest (BD) or FlowJo (Treestar).

HIV-1 Production. Using molecular clones of HIV-1 NL4-3 R5-tropic version ${ }^{34}$ was performed as described. ${ }^{25}$ 


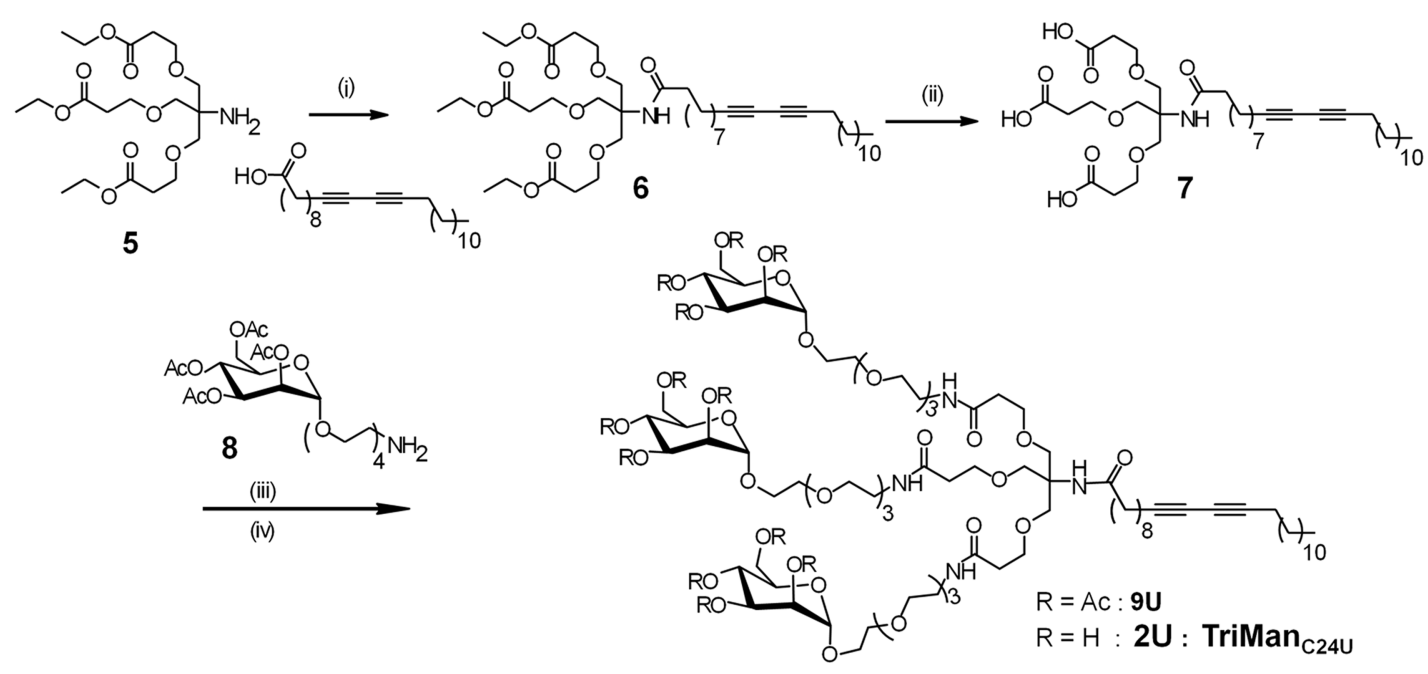

Figure 2. Synthesis of unsaturated $\operatorname{TriMan}_{\mathrm{C} 24 \mathrm{U}}$ conjugate 2U. Conditions: (i) 10,12-Pentacosadiynoic acid, HOBt, DCC, ACN/THF, reflux, overnight, 57\%; (ii) $\mathrm{NaOH} 4 \mathrm{~N}, \mathrm{THF} / \mathrm{EtOH}$, RT, overnight, 94\%; (iii) HOBt, HBTU, DIPEA, THF, reflux, overnight, $65 \%$; (iv) $\mathrm{NaOCH}_{3}, \mathrm{MeOH}$ RT, $30 \mathrm{~min}, 98 \%$.

HIV-1 Trans-Infection. Mannoside glycolipids (1.0 or 0.5 $\mathrm{mM}$ stock solution in water) were serially diluted in water. Human DCs $\left(1 \times 10^{5}\right.$ in $\left.200 \mu \mathrm{L}\right)$ were pretreated with different concentrations of compounds, mannan (Sigma), or culture medium alone in RPMI 1640 medium containing 10\% FCS for $45 \mathrm{~min}$ at $37{ }^{\circ} \mathrm{C}$, prior to infection with HIV-1 (100 ng of p24Gag) for $3 \mathrm{~h}$. Excess free virus and molecules were removed by three washes. DCs were then cocultured with MAGI-CCR5 cells $\left(1 \times 10^{5}\right)$ at $37{ }^{\circ} \mathrm{C}$ plated in a 48 -well plate. After two days, viral infection of MAGI-CCR5 cells was measured following beta-galactosidase assays and enumerating blue cells by light microscopy. The trans-infection assays were repeated a minimum of three times, and the $\mathrm{IC}_{50}$ values determined using Kaleidagraph.

\section{RESULTS AND DISCUSSION}

Synthesis of the Trivalent Unsaturated Glycolipid Conjugate $2 \mathrm{U}$. We have previously reported that mannoside glycolipid conjugates $\mathrm{Man}_{\mathrm{C} 24} 1, \mathrm{Man}_{\mathrm{C} 24 \mathrm{U}} 1 \mathrm{U}$, and TriMan ${ }_{\mathrm{C} 24} 2$ (Figure 1) interact with the extracellular domain of DC-SIGN and inhibit trans-infection of HIV-1. ${ }^{25}$ We noticed that the unsaturated conjugate $\mathbf{1} \mathbf{U}$ formed micelles at a 10 -fold lower critical micelle concentration (CMC), compared to the saturated conjugate 1. Formation of micelles at a low concentration should optimize the number of mannose heads interacting with DC-SIGN. In order to decrease the CMC of the saturated $\operatorname{TriMan}_{\mathrm{C} 24} 2$, we synthesized the corresponding unsaturated conjugate $\operatorname{TriMan}_{\mathrm{C} 24 \mathrm{U}} \mathbf{2 U}$ (Figure 1). For this, Tris-(carboxyethoxyethyl) aminomethane 5 was reacted with 10,12-pentacosanodiynoic acid to afford the amide 6 that was hydrolyzed into the triacid 7. Compound 7 was reacted with amine 8 to afford conjugate $9 \mathrm{U}$. Removal of the acetates led to the final product $2 \mathbf{U}$ (Figure 2).

Finally, to further increase the number of mannose heads susceptible to interact with DC-SIGN, micelles of the unsaturated mono- and trimannosides $\mathbf{1 U}$ and $\mathbf{2 U}$ were photopolymerized, leading to the respective polymers IUP and 2UP.

Synthesis of Control Trivalent Glycolipid Conjugates 3 and 4. We have synthesized compound 3, TriMan ${ }_{\mathrm{C} 1}$ that lacks the C24-lipid chain, to better evaluate the involvement of the lipid chain in the binding properties and biological activity. In addition, to demonstrate the importance of the mannose moiety, we have synthesized the control compound 4, $\mathrm{TriGal}_{\mathrm{C} 24}$, in which the three mannose residues of $\operatorname{TriMan}_{\mathrm{C} 24}$ are replaced by three galactose residues. The synthesis pathways are described in Supporting Information (Figures S1, S2).

Physical Properties. All conjugates were soluble in water, thanks to the presence of the OEG hydrophilic linker. Below the CMC, mannoside glycolipids exist as single molecules. Above the CMC, the lipid chains segregate into micelles with lipids forming a hydrophobic core and the mannose heads forming a hydrophilic shell. We determined the CMC for each compound (Figure 3A). Saturated $\mathrm{Man}_{\mathrm{C} 24} 1$ and TriMan ${ }_{\mathrm{C} 24} 2$ auto-organized into micelles at a CMC of, respectively, 97 and $109 \mu \mathrm{M}$, as described. ${ }^{25}$ As expected, unsaturated $1 \mathrm{U}$ and $2 \mathrm{U}$ displayed roughly a 10 -fold lower CMC of respectively 13 and $6 \mu \mathrm{M}$.

Micelles are typically described as spherical, nanosized (10$100 \mathrm{~nm}$ ) supramolecular assemblies of amphiphilic molecules, yet smaller than other assemblies, such as liposomes (50-150 $\mathrm{nm})$ or polymeric nanoparticles $(10-1000 \mathrm{~nm}) .{ }^{35}$ The hydrodynamic radius and the size distribution of micelles and polymers of our conjugates were determined by dynamic light scattering (DLS) in water (Figure 3A). As an example, the profile for compound $\mathbf{1 U}$ is shown in Figure 3B. The hydrodynamic diameter of saturated $\operatorname{Man}_{\mathrm{C} 24} \mathbf{1}$ and $\operatorname{TriMan}_{\mathrm{C} 24}$ 2 was, respectively, 17 and $39 \mathrm{~nm}$. Unsaturated compounds $\mathbf{1 U}$ and $2 \mathrm{U}$ had both a lower value of $11 \mathrm{~nm}$. Polymers $1 \mathrm{UP}$ and 2UP had both a hydrodynamic diameter of $16 \mathrm{~nm}$. The compound $1 \mathrm{U}$ could be visualized as $10-20 \mathrm{~nm}$ large micelles by transmission electronic microscopy (TEM) (Figure 3C). In addition, we found that the size of the compounds were smaller in PBS than in water: the hydrodynamic diameter of $\mathbf{2}$ and $\mathbf{2} \mathbf{U}$ $(10 \mu \mathrm{M})$ were, respectively, 3.2 and $4.3 \mathrm{~nm}$. In PBS containing calcium chloride, as found in cell culture conditions, compounds became structured in large assemblies, since the hydrodynamic diameter of $\mathbf{2}$ and $\mathbf{2} \mathbf{U}$ were increased to, respectively, 356/742 and $860 \mathrm{~nm}$ (Figure S14).

Viability assays performed on a human cell line showed that saturated conjugates $\mathbf{1}$ and $\mathbf{2}$ exhibited no cytotoxicity up to 

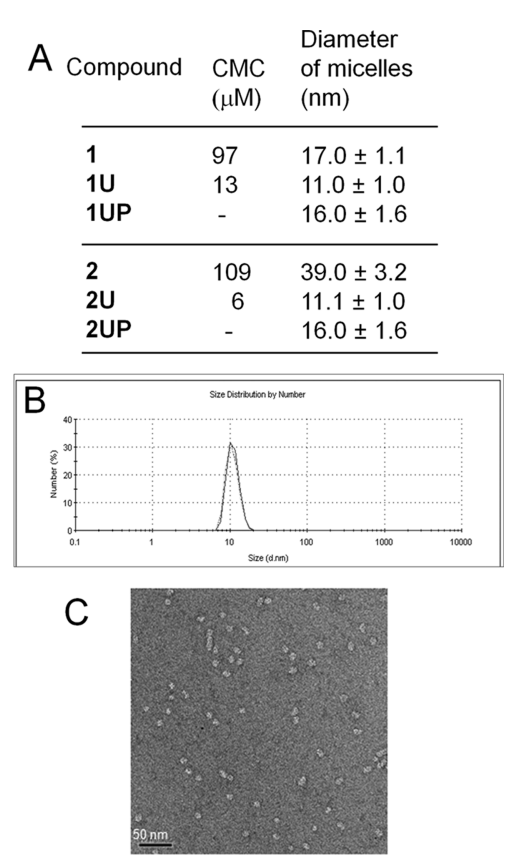

Figure 3. Characterization of mannoside glycolipid micelles: (A) CMC and diameter of micelles $(\mathrm{nm})$. (B) Size distribution for the micelles of $\mathbf{1 U}$. (C) TEM pictures for micelles of $\mathbf{1 U}$ (scale bar: 50 $\mathrm{nm})$.

$500 \mu \mathrm{M}$, the highest concentration tested. The unsaturated conjugate $\mathbf{1 U}$ and $\mathbf{2 U}$ had no adverse effect on cell viability up to, respectively, 125 and $250 \mu \mathrm{M}$ (Figure S15).

Affinities for DC-SIGN and MR. The ability of the conjugates to interact with DC-SIGN and the mannose receptor (MR) was measured by surface plasmon resonance (SPR). A CM5 sensor chip was functionalized with the CRD of DC-SIGN or MR, and increasing concentrations of the different compounds were injected over the chip surface. The resulting sensorgrams were evaluated to deduce the association $\left(k_{\text {on }}\right)$ and dissociation $\left(k_{\text {off }}\right)$ rate constants as well as the resulting dissociation equilibrium constant $\left(K_{\mathrm{D}}=k_{\text {off }} / k_{\mathrm{on}}\right)$ (Figure 4). To assess the specific binding, compounds were injected over the chip coated with BSA (Supporting Information, part D). $K_{\mathrm{d}}$ s higher than $13 \mu \mathrm{M}$ corresponded to nonspecific interactions. Our positive control, mannan, efficiently bound to the lectins, while compounds 3 and 4 , without the lipid chain or with a galactose replacing the mannose unit were unable to bind.

We found that all conjugates displayed better affinities for DC-SIGN than for MR (Figure 4C, E). The largest difference was observed with $\mathrm{Man}_{\mathrm{C} 24}$ 1, which bound with a high affinity to DC-SIGN ( $K_{\mathrm{D}}$ of $\left.0.32 \mu \mathrm{M}\right)$ but with a low affinity to MR $\left(K_{\mathrm{D}}\right.$ of $\left.100 \mu \mathrm{M}\right)$.

Concerning DC-SIGN, all mono- and trivalent conjugates exhibited a good affinity in the low micromolar range (Figure 4C). One mannose unit in $\operatorname{Man}_{\mathrm{C} 24} 1$ and $\operatorname{Man}_{\mathrm{C} 24 \mathrm{U}} 1 \mathrm{U}$ was sufficient for interaction, with a $K_{\mathrm{D}}$ in the low micromolar range. The unsaturated trivalent conjugate $\mathbf{2 U}$ presented a better affinity for DC-SIGN $\left(K_{\mathrm{D}}=0.3 \mu \mathrm{M}\right)$ than its saturated homologue $2\left(K_{\mathrm{D}}=3.2 \mu \mathrm{M}\right)$, suggesting that the unsaturated chain helped improve the interaction with DC-SIGN.

We next compared the behavior of single unsaturated molecules with their corresponding polymer. The low concentrations used in SPR assays for calculation of the constants correspond to single molecules, and not to micelles.
Results showed that polymerized IUP and single monoconjugate $1 \mathrm{U}$ displayed similar association constants $\left(k_{\text {on }}\right)$, but 1UP had a slower dissociation constant $\left(k_{\text {off }}\right)$ resulting in a lower $K_{\mathrm{D}}$. The $K_{\mathrm{D}}$ of the polymer 2UP was close to that of the nonpolymerized $2 \mathrm{U}$. As for $\mathrm{MR}$, polymers presented lower binding affinity to this lectin (higher $K_{\mathrm{D}} \mathrm{s}$ ) relative to the nonpolymerized conjugates (Figure 4E). These unexpected findings revealed that, with exception of the interaction of IUP with DC-SIGN, the presence of multiple mannose heads within polymerized conjugates decreased rather than increased their binding affinity for DC-SIGN and MR.

Effect of Calcium on Interactions with DC-SIGN. It has been established that the interaction of the CRD of DC-SIGN with high-mannose structures of glycoproteins is multivalent and calcium-dependent. ${ }^{15,16}$ To better understand the interactions of our conjugates with C-type lectins and the importance of the calcium binding site, we performed SPR analyses in the absence of calcium (Figure 4D, F). Surprisingly, results with DC-SIGN showed that the absence of calcium did not prevent binding, as $K_{\mathrm{D}} \mathrm{s}$ were still in the low micromolar range (Figure 4D). With $\operatorname{TriMan}_{\mathrm{C} 24}$ 2, the affinity for DCSIGN even improved in the absence of calcium. With MR, $K_{\mathrm{D}} \mathrm{S}$ remained in the micromolar range with $\mathbf{2 U}$ and $2 \mathrm{UP}$ (Figure $4 \mathrm{E}$ ). These results showed that, in vitro, our series of mannoside glycolipids could bind to the extracellular domain of DC-SIGN in a $\mathrm{Ca}^{2+}$-independent manner. Distinct studies have shown that when oligosaccharides are decorated with a Man $\alpha 1-$ $2 \mathrm{Man} \alpha$ structure, the binding by one mannose residue occurs at the principal $\mathrm{Ca}^{2+}$-binding site, while additional sugar residues enhance the affinity by providing additional contacts and a statistical entropic enhancement of binding. ${ }^{21}$ Similarly, the lipid chain of our conjugates may cooperate with the mannose head and enhance the affinity through additional interactions with various aminoacids of DC-SIGN.

To better evaluate the effect of calcium on the interactions of mannoside glycolipids with DC-SIGN, we measured the intrinsic fluorescence emission of DC-SIGN, in solution in PBS. In the presence of calcium, the fluorescence intensity decreased with increasing concentrations of compound 2 (Figure 5A). The intensity of fluorescence was converted into the fluorescence quenching parameter (Figure 5B), which led to the determination of the $K_{\mathrm{d}}$ (Figure $5 \mathrm{C}$ ), as described in Experimental Procedures. Interestingly, the model of two sitesfit led to two distinct $K_{\mathrm{d}} \mathrm{s}$ of 72 and $800 \mathrm{nM}$, likely reflecting distinct interactions of the mannose moiety and the lipid chain. In the absence of calcium, the intensity of fluorescence first decreased and then increased at about $1 \mu \mathrm{M}$. Thus, a $K_{\mathrm{d}}$ of 64 $\mathrm{nM}$ was calculated at low concentrations (Figure S11). Similarly, compound 2U interacted with DC-SIGN, with and without calcium, and displayed a respective $K_{d}$ of 180 and $>305$ $\mathrm{nM}$ (Figure 5D and S12-S13). These results confirmed the ability of our compounds to interact with the DC-SIGN protein in solution, with and without calcium.

Next, we investigated the requirement for calcium in a cellular assay. Conjugates $\mathbf{2}$ and 2UP were fluorescently labeled with Alexa-Fluor 633 (AF633). Monocytes that lack DC-SIGN expression, and DCs that express high levels of DC-SIGN ${ }^{25,36}$ were incubated in the presence of the labeled conjugates for $1 \mathrm{~h}$ and the mean fluorescent intensity (MFI) of the cells was determined by flow cytometry (Figure 6A). The intensity of fluorescence reflects both cell-surface binding and internalization. As expected, results showed that at $4{ }^{\circ} \mathrm{C}$ compounds bound to the cell surface at a low level, since internalization 
A

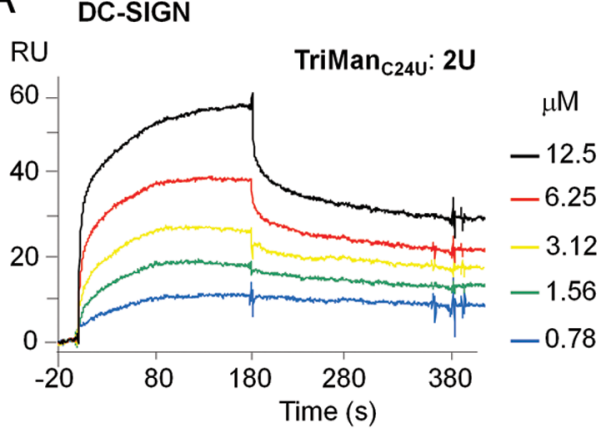

C DC-SIGN, with $\mathrm{CaCl}_{2}$

\begin{tabular}{|l|c|c|c|c|l|}
\hline Compound & $\mathrm{k}_{\text {on }}\left(\mathrm{M}^{-1} \mathrm{~s}^{-1}\right)$ & $\mathrm{k}_{\text {off }}\left(\mathrm{S}^{-1}\right)$ & $\mathrm{K}_{\mathrm{D}}(\mu \mathrm{M})$ & $\mathrm{R}_{\max }(\mathrm{RU})$ & $\mathrm{Chi}^{2}$ \\
\hline $\mathbf{1}$ & 273 & $0.0910^{-3}$ & 0.32 & 589 & 0.228 \\
$\mathbf{1 U}$ & 7180 & $2.7210^{-3}$ & 0.38 & 210 & 15.1 \\
$\mathbf{1 U P}$ & 7910 & $0.1310^{-3}$ & 0.02 & 278 & 14.8 \\
\hline $\mathbf{2}$ & 295 & $0.9410^{-3}$ & 3.19 & 305 & 0.331 \\
$\mathbf{2 U}$ & 2560 & $0.7110^{-3}$ & 0.28 & 157 & 42.8 \\
$\mathbf{2 U P}$ & 1550 & $0.4810^{-3}$ & 0.31 & 208 & 46.5 \\
\hline $\mathbf{3}$ & 6 & $0.4310^{-3}$ & 72.7 & 342 & 0.07 \\
$\mathbf{4}$ & 319 & $5.8210^{-3}$ & 18.2 & 23 & 1.01 \\
\hline \multicolumn{5}{|r|}{} \\
\hline
\end{tabular}

D DC-SIGN, without $\mathrm{CaCl}_{2}$

\begin{tabular}{|l|c|c|c|c|c|}
\hline $\mathbf{1}$ & 949 & $1.2010^{-3}$ & 1.26 & 96.5 & 0.898 \\
$\mathbf{1 U}$ & 183 & $2.1310^{-3}$ & 11.7 & 99.4 & 0.406 \\
$\mathbf{1 U P}$ & 2440 & $0.4910^{-3}$ & 0.02 & 8.77 & 0.349 \\
\hline $\mathbf{2}$ & 2510 & $1.0710^{-3}$ & 0.43 & 145 & 3.17 \\
$\mathbf{2 U}$ & 1870 & $1.2010^{-3}$ & 0.64 & 164 & 12.9 \\
$\mathbf{2 U P}$ & 1370 & $1.2610^{-3}$ & 0.92 & 187 & 14.2 \\
\hline $\mathbf{3}$ & No b. & - & - & - & - \\
$\mathbf{4}$ & 369 & $13.210^{-3}$ & 35.8 & 25.8 & 0.427 \\
\hline
\end{tabular}

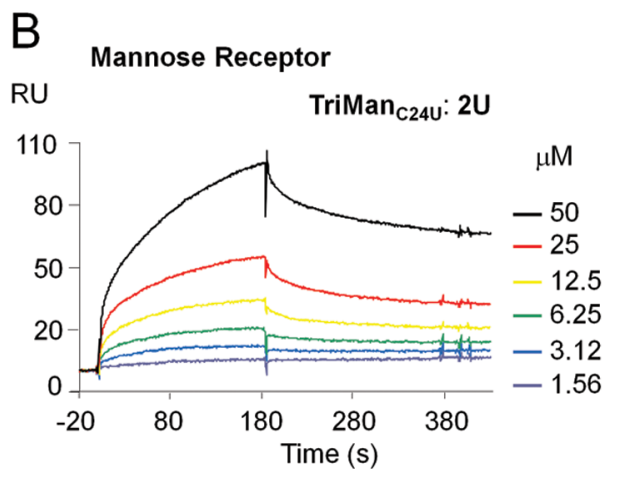

E Mannose Receptor, with $\mathrm{CaCl}_{2}$

\begin{tabular}{|l|l|l|l|l|l|}
\hline Compound & $\mathrm{K}_{\text {on }}\left(\mathrm{M}^{-1} \mathrm{~s}^{-1}\right)$ & $\mathrm{K}_{\text {off }}\left(\mathrm{s}^{-1}\right)$ & $\mathrm{K}_{\mathrm{D}}(\mu \mathrm{M})$ & $\mathrm{R}_{\max }(\mathrm{RU})$ & $\mathrm{Chi}^{2}$ \\
\hline $\mathbf{1}$ & Low b. & - & - & - & - \\
$\mathbf{1 U}$ & 520 & $2.2610^{-3}$ & 4.34 & 10.9 & 0.268 \\
$\mathbf{1 U P}$ & No b. & - & - & - & - \\
\hline $\mathbf{2}$ & 642 & $3.9410^{-3}$ & 6.13 & 32.3 & 0.326 \\
$\mathbf{2 U}$ & 729 & $1.2510^{-3}$ & 1.72 & 5.36 & 0.137 \\
$\mathbf{2 U P}$ & 1010 & $11.410^{-3}$ & 11.3 & 5.38 & 0.136 \\
\hline $\mathbf{3}$ & Low b. & - & - & - & - \\
$\mathbf{4}$ & 576 & $3.8610^{-3}$ & 6.71 & 10.3 & 0.127 \\
\hline
\end{tabular}

F Mannose Receptor, without $\mathrm{CaCl}_{2}$

\begin{tabular}{|l|l|l|l|l|l|}
\hline $\mathbf{1}$ & ND & & & & \\
1U & No b. & - & - & - & - \\
\hline $\mathbf{2}$ & Low b. & - & - & - & - \\
\hline $2 U$ & 244 & $9.9110^{-3}$ & 40.6 & 50.1 & 0.697 \\
2 UUP & 4060 & $11.310^{-3}$ & 2.78 & 6.32 & 0.263 \\
\hline 3 & 650 & $8.6310^{-3}$ & 13.3 & 5.17 & 0.086 \\
\hline 4 & No b. & - & - & - & - \\
\hline
\end{tabular}

Figure 4. Direct binding by surface plasmon resonance (SPR) of mannoside glycolipid conjugates to DC-SIGN or mannose receptor (MR) immobilized on a CMS sensor chip. (A, B) Sensorgram of the binding of $\mathbf{2 U}$ to DC-SIGN and MR immobilized via amino groups. The binding response (in RU) was recorded as a function of time. (C, D, E, F) Kinetic parameters of interactions determined in the presence (C, E) or absence $(\mathrm{D}, \mathrm{F})$ of $\mathrm{CaCl}_{2}$. As a positive control, binding of mannan was detected at $10 \mu \mathrm{g} / \mathrm{mL}$ (corresponding to $62 \mu \mathrm{M}$ of mannose units) in the presence of $\mathrm{CaCl}_{2}$. Mannan was unable to bind up to $280 \mu \mathrm{M}$ of mannose units in the absence of $\mathrm{CaCI}_{2} \cdot k_{\text {on }}$, kinetic association rate; $k_{\text {off }}$, kinetic dissociation rate; $K_{\mathrm{D}}$, equilibrium dissociation constant; $R_{\max }(\mathrm{RU})$, maximal response expressed as resonance units; $\chi^{2}$, chi square value. 1:1 Langmuir binding model was used for all compounds. "Low b.": Low binding. "No b.": No binding. ND: not determined.

does not occur at this temperature. At $37{ }^{\circ} \mathrm{C}$, the intensity of fluorescence was increased, as a consequence of the internalization of the compounds in addition to cell surface binding. DCs showed strong and dose-dependent interactions with both conjugates, reflecting the efficient binding to DC-SIGN, and to a lower extent to MR. Monocytes interacted with conjugates, albeit at much lower levels; this binding may depend on other receptors, such as heparan sulfates. ${ }^{37}$

To examine the importance of calcium for DCs-conjugates interactions, DCs were incubated with the labeled compounds in the presence or absence of EDTA (Figure 6B). Mannan that binds to DC-SIGN in a calcium-dependent manner (see legend of Figure 4) was also labeled with AF633 and used as a control. Interactions of DCs with mannan were decreased from $100 \%$ to $45 \%$ in the presence of EDTA. A similar inhibition ( 50\%) was seen for $\mathbf{2}$ and 2UP. These results suggest that interactions of the conjugates with DC-SIGN expressed at the DC cell surface are dependent on the calcium binding site of the CRD.

Finally, we examined whether mannan can compete with 2 and 2UP. DCs that were preincubated with $1 \mathrm{mM}$ mannan for
$30 \mathrm{~min}$ at $37{ }^{\circ} \mathrm{C}$ showed a $55 \%$ decrease in their ability to bind 2 and 2UP (Figure 6C). This potent, but incomplete, inhibition suggests that interactions of $\mathbf{2}$ and $\mathbf{2 U P}$ with their target receptor(s) on DCs mostly rely on their mannose moiety.

Comparison of Micelles and Polymers for Inhibition of HIV-1 trans-Infection. We investigated the ability of the conjugates to inhibit HIV-1 trans-infection, mediated by infected human DCs. These cells mimic in vivo conditions of viral infection by mucosal DCs. The DCs were pretreated with the different compounds for $45 \mathrm{~min}$ at $37{ }^{\circ} \mathrm{C}$, before exposure to HIV-1 (R5 strain). After $3 \mathrm{~h}$ of incubation, cells were extensively washed to remove unbound virions and compounds and were then cocultured with reporter MAGI-CCR5 cells. These cells express the CD4 receptor and the CCR5 coreceptor required for cell entry and fusion of HIV-1 R5. They also express an integrated copy of the HIV long terminal repeat fused to the beta-galactosidase reporter gene and thus allow precise quantification of HIV-1 replication by detection of betagalactosidase activity. 

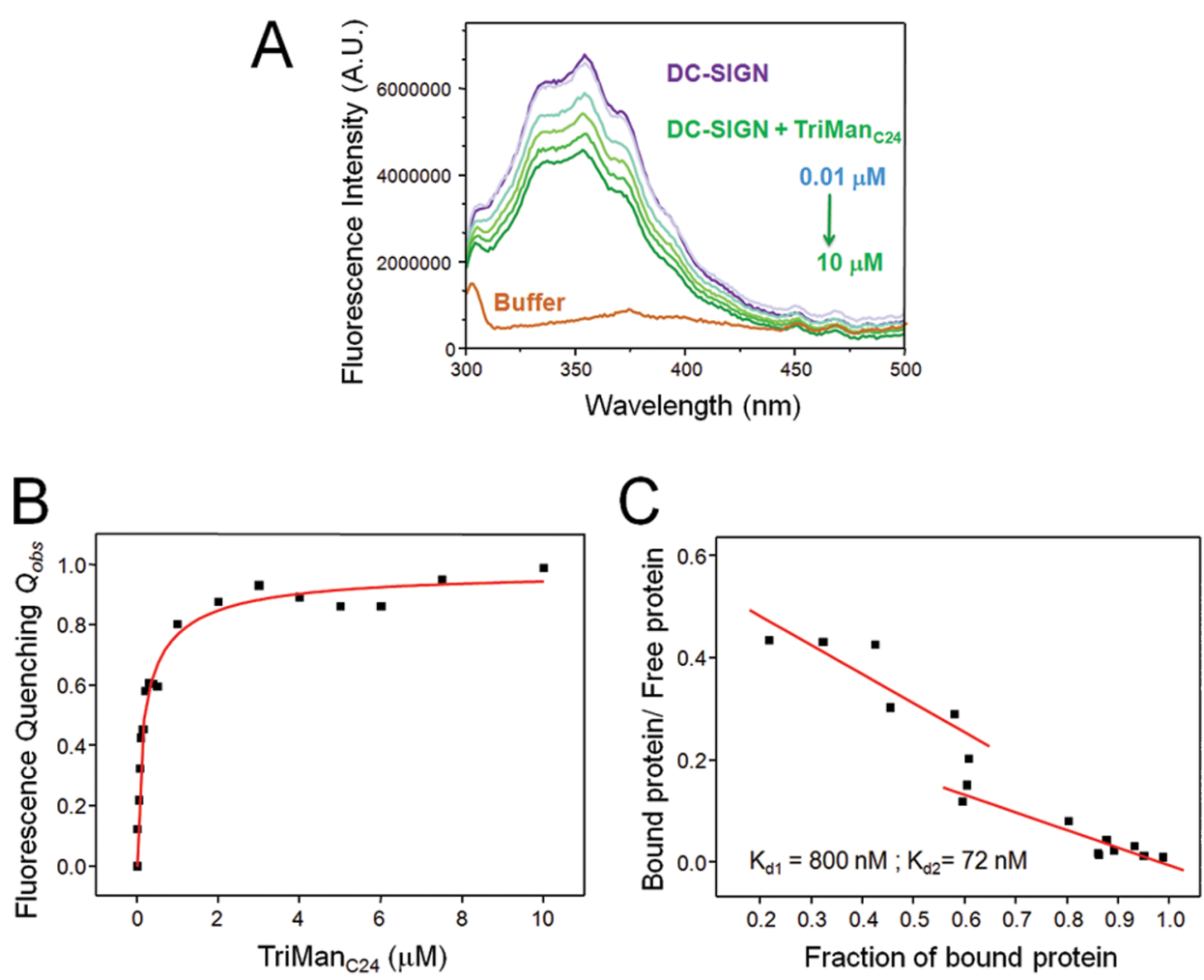

\begin{tabular}{|c|c|c|c|}
\hline & $\begin{aligned} & \text { DC-SIGN } \\
&+ \text { Conjugate } \\
&\end{aligned}$ & $\begin{array}{c}\mathrm{k}_{\mathrm{d}}(\mu \mathrm{M}) \\
(1 \text { site fit })\end{array}$ & $\begin{array}{c}k_{d}(\mu M) \\
(2 \text { sites fit })\end{array}$ \\
\hline$+\mathrm{CaCl}_{2}$ & $\begin{array}{l}\text { 2: } \operatorname{TriMan}_{\mathrm{C24}} \\
\text { 2U: } \operatorname{TriMan}_{\mathrm{C} 24 \mathrm{U}}\end{array}$ & $\begin{array}{l}0.150 \\
0.180\end{array}$ & $\begin{array}{c}0.800 ; 0.072 \\
-\end{array}$ \\
\hline$-\mathrm{CaCl}_{2}$ & $\begin{array}{l}\text { 2: } \operatorname{TriMan}_{\mathrm{C} 24} \\
\text { 2U:TriMan } \\
\mathrm{C} 24 \mathrm{U}\end{array}$ & $\begin{array}{c}0.064 \\
>0.305\end{array}$ & - \\
\hline
\end{tabular}

Figure 5. Binding of mannoside glycolipid conjugates to DC-SIGN in solution measured by emission fluorescence spectroscopy. (A) Emission fluorescence spectra of DC-SIGN in solution (PBS with $5 \mathrm{mM} \mathrm{CaCl}_{2}$ ) and in the presence of increasing concentrations of conjugate 2 . Excitation wavelength was set at $295 \mathrm{~nm}$. (B) The fluorescence intensity $I$ was then converted into the fluorescence quenching parameter $Q_{\text {obs }}$ (as described in Experimental Procedures). (C) Determination of the equilibrium dissociation constant, $K_{\mathrm{d}}$, using the one-site and two-sites model fit. (D) $K_{\mathrm{d}}$ of DCSIGN with indicated conjugates, in the presence and absence of $\mathrm{CaCl}_{2}$.

We first tested the compounds at 10 and $100 \mu \mathrm{M}$ (Figure 7). As expected, the control compounds 3 and 4 were unable to inhibit HIV-1 trans-infection. All trivalent conjugates were more active than monovalent conjugates, confirming our previous report. $^{25}$ Surprisingly, the polymer 1UP was totally inactive. Even at the highest concentration of $100 \mu \mathrm{M}$, this polymer only marginally affected trans-infection, in contrast with nonpolymerized $1 \mathrm{U}$. The disadvantage of a rigid polymerized structure was confirmed with polymer $2 \mathbf{U P}$, which displayed a lower inhibitory activity, relative to the micelles formed by $\mathbf{2} \mathbf{U}$. These results showed that within a cellular context, rigid polymeric assemblies of mannoside glycolipids were unable to efficiently protect MAGI-CCR5 cells from HIV-1 transinfection.

Comparison of Unsaturated and Saturated Conjugates for Inhibition of HIV-1 trans-Infection. Dose- response experiments were performed to compare the inhibitory capacity of unsaturated and saturated conjugates. We determined the concentration at which there was 50\% inhibition of trans-infection $\left(\mathrm{IC}_{50}\right)$. Monomannoside glycolipids 1 and $\mathbf{1 U}$ were active at concentrations higher than $1 \mu \mathrm{M}$, and displayed $\mathrm{IC}_{50}$ s of, respectively, 120 and $61 \mu \mathrm{M}$ (Figure 8A). At high concentrations, they reduced viral trans-infection down to a residual level of about $20 \%$.

Trivalent conjugates $\mathbf{2}$ and $\mathbf{2} \mathbf{U}$ exhibited a powerful inhibitory activity, as reflected by low $\mathrm{IC}_{50} \mathrm{~s}$ of, respectively, $0.501 \mu \mathrm{M}$ and $0.305 \mu \mathrm{M}$ (Figure $8 \mathrm{~B}$ ). Unsaturated $2 \mathrm{U}$ was more active than saturated 2 at high concentrations, since the residual level of infection was reduced, respectively, to $2 \%$ and $20 \%$. The better inhibitory activity of unsaturated $2 \mathrm{U}$ correlated with its better affinity for DC-SIGN, in agreement with our SPR data (Figure 4C). 
A

$37^{\circ} \mathrm{C}$

$4^{\circ} \mathrm{C}$

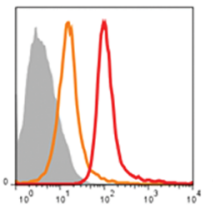

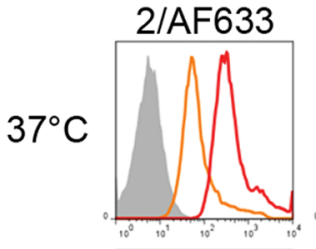
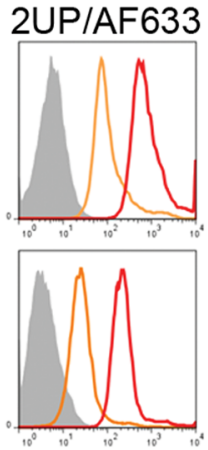

B

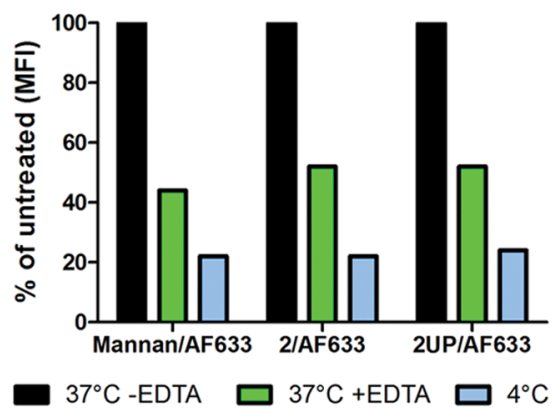

Monocytes

2/AF633 2UP/AF633
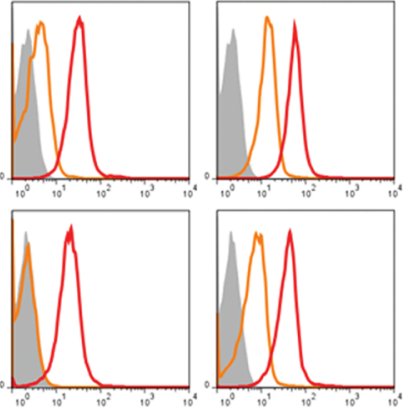

$0 / 5 / 50 \mu \mathrm{M}$

C

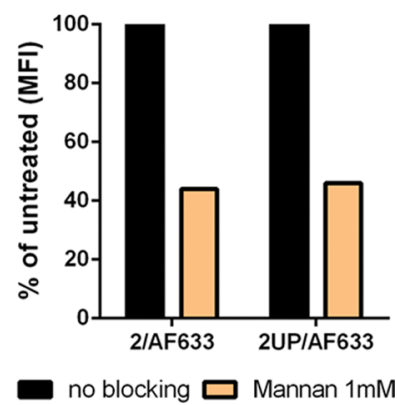

Figure 6. Interactions of mannoside glycolipid conjugates with human DCs and monocytes measured by flow cytometry. (A) DCs and monocytes were incubated with fluorescently labeled conjugates 2/AF633 or 2UP/AF633, for $1 \mathrm{~h}$ at either $4{ }^{\circ} \mathrm{C}$ or at $37{ }^{\circ} \mathrm{C}$. One representative experiment out of three with similar results is shown. (B) Comparison of fluorescently labeled mannan or conjugates 2/AF633 and 2UP/AF633 (5 $\mu$ M) interactions with DCs after a $1 \mathrm{~h}$ incubation at 4 or $37^{\circ} \mathrm{C}$, in the absence or presence of EDTA at $37^{\circ} \mathrm{C}$. (C) DCs were incubated with mannan $(1$ $\mathrm{mM}$ ) for $30 \mathrm{~min}$ at $37^{\circ} \mathrm{C}$, before addition of fluorescently labeled conjugates 2/AF633 and 2UP/AF633 (5 $\left.\mu \mathrm{M}\right)$ for $1 \mathrm{~h}$ at $37^{\circ} \mathrm{C}$. Values were normalized to the mean fluorescence intensity (MFI) measured at $37^{\circ} \mathrm{C}$ in the absence of EDTA. One representative experiment out of three with similar results is shown.

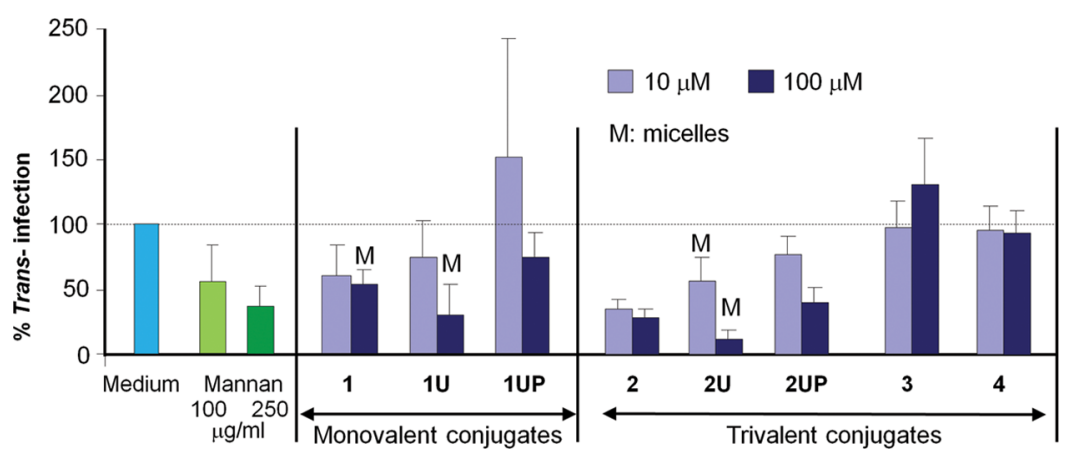

Figure 7. Comparison of micelles and polymers of mannoside glycolipid conjugates for inhibition of HIV-1 trans-infection. Human DCs were pretreated with the indicated compounds for $30 \mathrm{~min}$ at $37^{\circ} \mathrm{C}$ and infected with HIV-1 R5. After extensive washes, DCs were cocultured with MAGICCR5 cells for 2 days. Viral trans-infection was quantified. Values were normalized relative to $100 \%$ infection obtained with medium alone. Mannan was used as a positive control. Values are means \pm SE from data obtained from at least three independent experiments.

We observed that the dose-response inhibition profile was different for conjugates $\mathbf{2}$ and $\mathbf{2 U}$ (Figure $8 \mathrm{~B}$ ). The saturated $\mathbf{2}$ displayed a progressive decrease with a constant slope $a$, between 0.01 and $250 \mu \mathrm{M}$. The unsaturated $2 \mathrm{U}$ displayed two distinct slopes: slope $a$ at low concentrations ( 0.01 to $1 \mu \mathrm{M})$, and a faster slope $b$ at high concentrations (10 to $250 \mu \mathrm{M})$. The cutoff range between 1 and $10 \mu \mathrm{M}$ corresponds to the CMC $(6.4 \mu \mathrm{M})$. Similarly for compounds $\mathbf{1 U}$ and $2 \mathbf{U}$, a fast slope $b$ was detected at concentrations above the CMC, which shows that micelles induce a better inhibition rate compared with single molecules (Figure $8 \mathrm{C}$ ). This result revealed that single molecules and micelles induce an antiviral inhibitory activity with distinct efficiencies, reflected by the respective slow slope $a$ and fast slope $b$. Thus, our findings point out a clear correlation between the molecular assembly of a conjugate-either single molecules or a micelle-and its antiviral inhibitory activity. They demonstrate that multivalent mannose presentation in micelles is most efficient for the biological inhibition of viral transmission. 

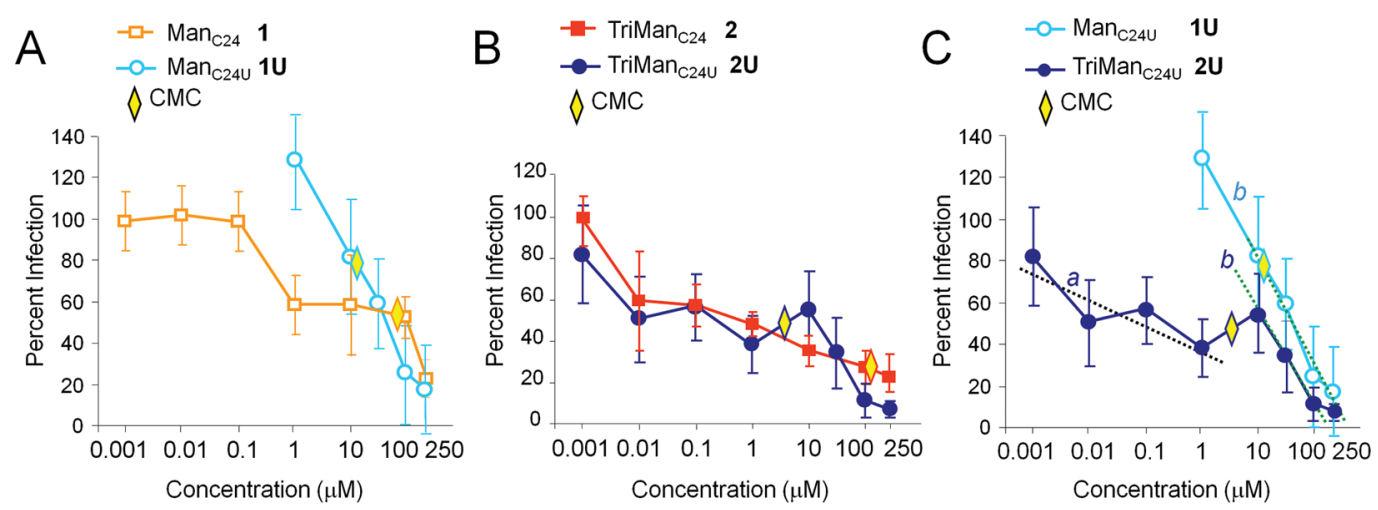

Figure 8. Dose-response inhibition of HIV-1 trans-infection by mannoside glycolipid conjugates. HIV-1 trans-infections between human DCs and MAGI-CCR5 cells were performed as described in Figure 7, at the indicated concentrations with (A) monovalent-conjugates, (B) trivalent conjugates, and (C) unsaturated mono- and trivalent-conjugates. The critical micelle concentration (CMC) is indicated. Slopes $a$ and $b$ are indicated.

\section{CONCLUSIONS}

Our studies revealed that mannoside glycolipids display the highest biological antiviral activity when structured as dynamic micelles in equilibrium with single molecules, rather than as rigid cross-linked polymers. Moreover, our data have demonstrated a clear correlation between the structure of the molecular assembly_as a single molecule, a micelle or a polymer-and its corresponding biological activity.

Our SPR results first revealed a novel aspect of the interactions between mannoside glycolipid conjugates and the DC-SIGN protein. While interactions with C-type lectins are dependent on the proper conformation of their calcium-binding site, as shown with mannan, our conjugates were able to interact in vitro with the CRD of monomeric DC-SIGN both in the presence and the absence of calcium, with $K_{\mathrm{D}} \mathrm{s}$ in the micromolar range. Similarly, steady-state fluorescence spectroscopy data confirmed that interactions occur with DC-SIGN in solution, with and without calcium, with $K_{d} s$ in the low micromolar range. This result agrees with previous studies reporting that proteins of the C-type lectin family can bind some sugars in the absence of calcium: CLEC5A does not have a full set of calcium-coordinating and carbohydrate binding sites; ${ }^{38}$ dectin- 1 binds $\beta$-glucan oligosaccharides in the absence of calcium; ${ }^{39}$ concerning DC-SIGN, our finding emphasizes the role of the lipid chain present in our conjugates, which may interact with a hydrophobic pocket of the protein located outside of the calcium binding site. The emission fluorescence spectra data revealed two distinct $K_{\mathrm{d}} \mathrm{s}$ for $\mathrm{TriMan}_{\mathrm{C} 24}$, which likely reflect the binding of the mannose moiety and the lipid chain. However, in contrast with our SPR and fluorescence data, the calcium dependence was observed in a cellular environment. Our DLS data have revealed that in the presence of calcium, the conjugates form large structured assemblies. One may thus envision that larger conjugates display optimal interactions with DC-SIGN expressed at the surface of DCs.

Mannoside glycolipid conjugates exist in the form of either single molecules or assemble into self-organized micelles, which both target DC-SIGN and block HIV-1 trans-infection, as shown previously. ${ }^{25}$ The affinity of these conjugates for DCSIGN and their inhibition of HIV-1 trans-infection are based on the cooperation between the lipid chain and the linked mannose moiety. Thanks to this cooperation, monomannoside glycolipid conjugates (1 and $\mathbf{1 U}$ ) target DC-SIGN and inhibit HIV-1 trans-infection even as single molecules. The inhibitory activity was improved by multivalent presentation of three mannoses in the saturated TriMan $_{\mathrm{C} 24}$ (conjugate 2). However, its CMC of $109 \mu \mathrm{M}$ lead to micelles formation at a high concentration. The design and synthesis of unsaturated TriMan $_{\mathrm{C} 24 \mathrm{U}}$ (conjugate $2 \mathrm{U}$ ) helped reduce the CMC to 6 $\mu \mathrm{M}$. As expected, formation of micelles at a lower concentration improved the biological efficiency: $\mathbf{2} \mathbf{U}$ was most effective for reducing trans-infection to a minimal residual level, at high concentrations. These data highlight the importance of designing molecules able to self-assemble into micelles at the lowest CMC possible.

Our data further demonstrate that formation of a scaffold offering a multivalent mannose presentation reduced HIV-1 trans-infection mostly when the structure was organized as dynamic micelles, in equilibrium with single molecules. In contrast, when conjugates were structured as rigid photopolymerized cross-linked polymers, they were much less effective as inhibitors. A putative model accounting for these findings is presented in the TOC graphic. Single conjugates display high affinity interactions with DC-SIGN, thanks to multiple interactions of their mannose head and lipid chain. However, optimal interaction with DC-SIGN is hampered by the low concentration of single molecules, which results in low antiviral activity (left scheme). Micelles possess two advantages: first, they concentrate multiple conjugates susceptible to target DC-SIGN; second, within micelles, lipid chains are free to move into an optimal interaction with DC-SIGN. Thus, the high conjugate concentrations and the dynamic properties of micelles lead to optimal interactions, which result in the highest antiviral activity (central scheme). However, within photopolymerized cross-linked polymers, lipid chains are caged inside the macromolecular structure, thus unable to interact with a hydrophobic pocket of the protein located outside of the calcium binding site of DC-SIGN. Due to their rigid structure, polymers have the disadvantage to target DC-SIGN exclusively via their mannose moieties, which leads to low antiviral activity (right scheme). Together, these data highlight the importance of designing conjugates susceptible of dynamic possibilities, and enough freedom for adjusting to optimal interactions with a cellular receptor. The fact that micelles are more effective than the corresponding cross-linked polymers suggests that building a level of dynamic plasticity into the multivalent presentation of the ligand helps to adapt to the complex membrane organization of the receptor. However, the inactivity of the polymer could also result from other structural feature of the 
material, for instance, excessive reticulation, which prevents exposure of the sugar at the polymer surface.

Further studies are required to investigate the ability of our conjugates to prevent mucosal HIV-1 transmission in humans. It will also be important to assess whether our compounds do not impair the mucosal integrity or induce inflammatory processes. Once the physiological safety of these conjugates is shown, they could be considered as novel tools for HIV prophylaxis.

\section{ASSOCIATED CONTENT}

\section{S Supporting Information}

Full synthetic and characterization details of the compounds including NMR spectra, emission fluorescence spectroscopy, DLS and cell viability assays are provided. This material is available free of charge via the Internet at http://pubs.acs.org.

\section{AUTHOR INFORMATION}

\section{Corresponding Author}

*E-mail: e.schaeffer@ibmc-cnrs.unistra.fr (E.S.).

\section{Author Contributions}

The first two authors contributed equally to this work.

\section{Funding}

Notes

The authors declare no competing financial interest.

\section{ACKNOWLEDGMENTS}

This work was supported by the "Centre National de la Recherche Scientifique” (CNRS). L.D. was supported by a fellowship from the University of Strasbourg. The French National Agency for Research on AIDS and Viral Hepatitis (ANRS) is acknowledged for a short-term support to V.F. V.F. and D.S. were also supported by the Laboratory of Excellence Medalis, Initiative of Excellence (IdEx), Strasbourg University, France.We are grateful to P. Pévet and S. Reibel-Foisset for the use of the A3/L3 platform of the Institut Féderatif de Recherches (IFR37), Strasbourg. We thank the AIDS Research and Reference Reagent Program, Division of AIDS, NIAID, $\mathrm{NIH}$, for MAGI-CCR5 cells.

\section{ABBREVIATIONS}

DC-SIGN, dendritic cell-specific ICAM-3-grabbing nonintegrin; DCs, dendritic cells; HIV-1, human immunodeficiency virus type-1; CRD, carbohydrate recognition domain; CMC, critical micelle concentration; OEG, oligo(ethylene glycol); $\mathrm{SPR}$, surface plasmon resonance

\section{REFERENCES}

(1) du Toit, L. C., Pillay, V., and Choonara, Y. E. (2010) Nanomicrobicides: challenges in drug delivery, patient ethics and intellectual property in the war against HIV/AIDS. Adv. Drug Delivery Rev. 62, 532-546.

(2) Hladik, F., and McElrath, M. J. (2008) Setting the stage: host invasion by HIV. Nat. Rev. Immunol. 8, 447-457.

(3) Haase, A. T. (2010) Targeting early infection to prevent HIV-1 mucosal transmission. Nature 464, 217-223.

(4) Hu, J., Gardner, M. B., and Miller, C. J. (2000) Simian immunodeficiency virus rapidly penetrates the cervicovaginal mucosa after intravaginal inoculation and infects intraepithelial dendritic cells. J. Virol. 74, 6087-6095.

(5) Gurney, K. B., Elliott, J., Nassanian, H., Song, C., Soilleux, E., McGowan, I., Anton, P. A., and Lee, B. (2005) Binding and transfer of human immunodeficiency virus by DC-SIGN + cells in human rectal mucosa. J. Virol. 79, 5762-5773.

(6) Wilkinson, J., and Cunningham, A. L. (2006) Mucosal transmission of HIV-1: first stop dendritic cells. Curr. Drug Targets 7, 1563-1569.

(7) Yamamoto, T., Tsunetsugu-Yokota, Y., Mitsuki, Y. Y., Mizukoshi, F., Tsuchiya, T., Terahara, K., Inagaki, Y., Yamamoto, N., Kobayashi, K., and Inoue, J. (2009) Selective transmission of R5 HIV-1 over X4 HIV-1 at the dendritic cell-T cell infectious synapse is determined by the T cell activation state. PLoS Pathog. 5, e1000279.

(8) Geijtenbeek, T. B., Kwon, D. S., Torensma, R., van Vliet, S. J., van Duijnhoven, G. C., Middel, J., Cornelissen, I. L., Nottet, H. S., KewalRamani, V. N., Littman, D. R., Figdor, C. G., and van Kooyk, Y. (2000) DC-SIGN, a dendritic cell-specific HIV-1-binding protein that enhances trans-infection of T cells. Cell 100, 587-597.

(9) Piguet, V., and Steinman, R. M. (2007) The interaction of HIV with dendritic cells: outcomes and pathways. Trends Immunol. 28, 503-510.

(10) Wu, L., and KewalRamani, V. N. (2006) Dendritic-cell interactions with HIV: infection and viral dissemination. Nat. Rev. Immunol. 6, 859-868.

(11) Geijtenbeek, T. B., and van Kooyk, Y. (2003) DC-SIGN: a novel HIV receptor on DCs that mediates HIV-1 transmission. Curr. Top. Microbiol. Immunol. 276, 31-54.

(12) Arrighi, J. F., Pion, M., Wiznerowicz, M., Geijtenbeek, T. B., Garcia, E., Abraham, S., Leuba, F., Dutoit, V., Ducrey-Rundquist, O., van Kooyk, Y., Trono, D., and Piguet, V. (2004) Lentivirus-mediated RNA interference of DC-SIGN expression inhibits human immunodeficiency virus transmission from dendritic cells to T cells. J. Virol. 78, 10848-10855.

(13) Chung, N. P., Breun, S. K., Bashirova, A., Baumann, J. G., Martin, T. D., Karamchandani, J. M., Rausch, J. W., Le Grice, S. F., Wu, L., Carrington, M., and Kewalramani, V. N. (2010) HIV-1 transmission by dendritic cell-specific ICAM-3-grabbing nonintegrin (DCSIGN) is regulated by determinants in the carbohydrate recognition domain that are absent in liver/lymph node-SIGN (L-SIGN). J. Biol. Chem. 285, 2100-2112.

(14) Cavrois, M., Neidleman, J., Kreisberg, J. F., and Greene, W. C. (2007) In vitro derived dendritic cells trans-infect CD4 $\mathrm{T}$ cells primarily with surface-bound HIV-1 virions. PLoS Pathog. 3, e4.

(15) Feinberg, H., Mitchell, D. A., Drickamer, K., and Weis, W. I. (2001) Structural basis for selective recognition of oligosaccharides by DC-SIGN and DC-SIGNR. Science 294, 2163-2166.

(16) Mitchell, D. A., Fadden, A. J., and Drickamer, K. (2001) A novel mechanism of carbohydrate recognition by the C-type lectins DCSIGN and DC-SIGNR. Subunit organization and binding to multivalent ligands. J. Biol. Chem. 276, 28939-28945.

(17) Geijtenbeek, T. B., and van Kooyk, Y. (2003) Pathogens target DC-SIGN to influence their fate DC-SIGN functions as a pathogen receptor with broad specificity. APMIS 111, 698-714.

(18) Geijtenbeek, T. B., den Dunnen, J., and Gringhuis, S. I. (2009) Pathogen recognition by DC-SIGN shapes adaptive immunity. Future Microbiol. 4, 879-890.

(19) Hong, P. W., Flummerfelt, K. B., de Parseval, A., Gurney, K., Elder, J. H., and Lee, B. (2002) Human immunodeficiency virus envelope (gp120) binding to DC-SIGN and primary dendritic cells is carbohydrate dependent but does not involve $2 \mathrm{G} 12$ or cyanovirin binding sites: implications for structural analyses of gp120-DC-SIGN binding. J. Virol. 76, 12855-12865.

(20) Su, S. V., Gurney, K. B., and Lee, B. (2003) Sugar and spice: viral envelope-DC-SIGN interactions in HIV pathogenesis. Curr. HIV Res. 1, 87-99.

(21) Feinberg, H., Castelli, R., Drickamer, K., Seeberger, P. H., and Weis, W. I. (2007) Multiple modes of binding enhance the affinity of DC-SIGN for high mannose N-linked glycans found on viral glycoproteins. J. Biol. Chem. 282, 4202-4209.

(22) Anderluh, M., Jug, G., Svajger, U., and Obermajer, N. (2012) DC-SIGN antagonists, a potential new class of anti-infectives. Curr. Med. Chem. 19, 992-1007. 
(23) Tabarani, G., Reina, J. J., Ebel, C., Vives, C., Lortat-Jacob, H., Rojo, J., and Fieschi, F. (2006) Mannose hyperbranched dendritic polymers interact with clustered organization of DC-SIGN and inhibit gp120 binding. FEBS Lett. 580, 2402-2408.

(24) Wang, S. K., Liang, P. H., Astronomo, R. D., Hsu, T. L., Hsieh, S. L., Burton, D. R., and Wong, C. H. (2008) Targeting the carbohydrates on HIV-1: Interaction of oligomannose dendrons with human monoclonal antibody 2G12 and DC-SIGN. Proc. Natl. Acad. Sci. (U.S.A.) 105, 3690-3695.

(25) Dehuyser, L., Schaeffer, E., Chaloin, O., Mueller, C. G., Baati, R., and Wagner, A. (2012) Synthesis of novel mannoside glycolipid conjugates for inhibition of HIV-1 trans-infection. Bioconjugate Chem. 23, 1731-1739.

(26) Ciobanu, M., Huang, K. T., Daguer, J. P., Barluenga, S., Chaloin, O., Schaeffer, E., Mueller, C. G., Mitchell, D. A., and Winssinger, N. (2011) Selection of a synthetic glycan oligomer from a library of DNAtemplated fragments against DC-SIGN and inhibition of HIV gp120 binding to dendritic cells. Chem. Commun. 47, 9321-9323.

(27) Martinez-Avila, O., Hijazi, K., Marradi, M., Clavel, C., Campion, C., Kelly, C., and Penades, S. (2009) Gold manno-glyconanoparticles: multivalent systems to block HIV-1 gp120 binding to the lectin DCSIGN. Chem.-Eur. J. 15, 9874-9888.

(28) Arnaiz, B., Martinez-Avila, O., Falcon-Perez, J. M., and Penades, S. (2012) Cellular uptake of gold nanoparticles bearing HIV gp120 oligomannosides. Bioconjugate Chem. 23, 814-825.

(29) Sattin, S., Daghetti, A., Thepaut, M., Berzi, A., Sanchez-Navarro, M., Tabarani, G., Rojo, J., Fieschi, F., Clerici, M., and Bernardi, A. (2010) Inhibition of DC-SIGN-mediated HIV infection by a linear trimannoside mimic in a tetravalent presentation. ACS Chem. Biol. 5, 301-312.

(30) Berzi, A., Reina, J. J., Ottria, R., Sutkeviciute, I., Antonazzo, P., Sanchez-Navarro, M., Chabrol, E., Biasin, M., Trabattoni, D., Cetin, I., Rojo, J., Fieschi, F., Bernardi, A., and Clerici, M. (2012) A glycomimetic compound inhibits DC-SIGN-mediated HIV infection in cellular and cervical explant models. AIDS 26, 127-137.

(31) Morin, E., Nothisen, M., Wagner, A., and Remy, J.-S. (2011) Cationic polydiacetylene micelles for gene delivery. Bioconjugate Chem. 22, 1916-1923.

(32) Perino, A., Klymchenko, A., Morere, A., Contal, E., Rameau, A., Guenet, J.-M., Mély, Y., and Wagner, A. (2011) Structure and behaviour of polydiacetylene-based micelles. Macromol. Chem. Phys. 212, 111-117.

(33) Chackerian, B., Long, E. M., Luciw, P. A., and Overbaugh, J. (1997) Human immunodeficiency virus type 1 coreceptors participate in postentry stages in the virus replication cycle and function in simian immunodeficiency virus infection. J. Virol. 71, 3932-3939.

(34) Schaeffer, E., Soros, V. B., and Greene, W. C. (2004) Compensatory link between fusion and endocytosis of human immunodeficiency virus type 1 in human CD4 T lymphocytes. J. Virol. 78, 1375-1383.

(35) Gunaseelan, S., Gunaseelan, K., Deshmukh, M., Zhang, X., and Sinko, P. J. (2010) Surface modifications of nanocarriers for effective intracellular delivery of anti-HIV drugs. Adv. Drug Delivery Rev. 62, $518-531$.

(36) Relloso, M., Puig-Kroger, A., Pello, O. M., Rodriguez-Fernandez, J. L., de la Rosa, G., Longo, N., Navarro, J., Munoz-Fernandez, M. A., Sanchez-Mateos, P., and Corbi, A. L. (2002) DC-SIGN (CD209) expression is IL-4 dependent and is negatively regulated by IFN, TGFbeta, and anti-inflammatory agents. J. Immunol. 168, 2634-2643.

(37) Vives, R. R., Imberty, A., Sattentau, Q. J., and Lortat-Jacob, H. (2005) Heparan sulfate targets the HIV-1 envelope glycoprotein gp120 coreceptor binding site. J. Biol. Chem. 280, 21353-21357.

(38) Watson, A. A., Lebedev, A. A., Hall, B. A., Fenton-May, A. E., Vagin, A. A., Dejnirattisai, W., Felce, J., Mongkolsapaya, J., Palma, A. S., Liu, Y., Feizi, T., Screaton, G. R., Murshudov, G. N., and O'Callaghan, C. A. (2011) Structural flexibility of the macrophage dengue virus receptor CLEC5A: implications for ligand binding and signaling. J. Biol. Chem. 286, 24208-24218.
(39) Palma, A. S., Feizi, T., Zhang, Y., Stoll, M. S., Lawson, A. M., Diaz-Rodriguez, E., Campanero-Rhodes, M. A., Costa, J., Gordon, S., Brown, G. D., and Chai, W. (2006) Ligands for the beta-glucan receptor, Dectin-1, assigned using "designer" microarrays of oligosaccharide probes (neoglycolipids) generated from glucan polysaccharides. J. Biol. Chem. 281, 5771-5779. 